\title{
Hydrophobization of cotton fabric with silanes with different substituents
}

\author{
T. Makowski $\mathbb{D}$
}

Received: 28 June 2019/Accepted: 26 September 2019/Published online: 10 October 2019

(C) The Author(s) 2019

\begin{abstract}
In this paper hydrophobization of cotton fabric with a range of silanes, differing in number of chlorine atoms and in other substituents, was explored. The fabric modification was carried out in silane solutions in anhydrous toluene and in n-hexane. Water contact angles were measured to characterize hydrophili/phobicity of the modified fabrics. Surfaces of the fibers were analyzed using SEM, EDS and ATR-FTIR. Treatment with dichlorodimethylsilane, dichloro(methyl)phenylsilane, 3-chloropropylmethyldichlorosilane and (3,3,3-trifluoropropyl)dichloromethylsilane resulted in hydrophobization, whereas trimethylchlorosilane and 3-aminopropyl(diethoxy)methylsilane were inefficient. Mechanisms of coating with the silanes were proposed. Dielectric spectroscopy of the modified fabric demonstrated that resistance was sensitive to efficiency of reactions removing water from the cotton fibers.
\end{abstract}

\section{Graphic abstract}

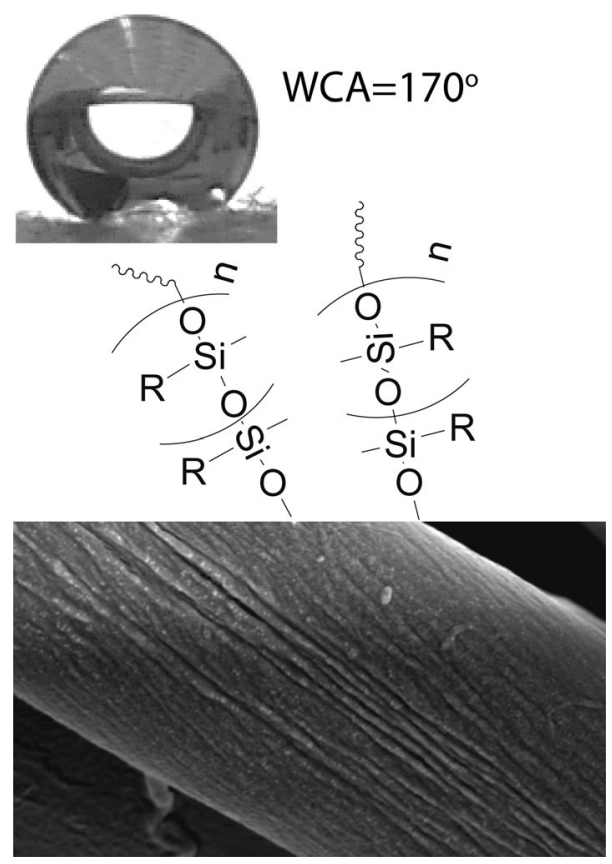

Keywords Cotton fabric - Superhydrophobicity · Silanes · Dielectric spectroscopy $\cdot$ ATR-FTIR

T. Makowski ( $\square)$

Centre of Molecular and Macromolecular Studies Polish Academy of Sciences, Sienkiewicza 112, 90-363 Lodz, Poland

e-mail: tomekmak@cbmm.lodz.pl 


\section{Introduction}

Cotton fibers are the most popular natural fibers used to produce a broad range of textiles. Being lightweight, porous and flexible, cotton textiles are widely used. Cotton is hydrophilic, which is an advantage in many applications. However, engineering of superhydrophobic textile surfaces gains significant scientific and industrial interest because of potential applications in outdoor wear and protective textiles. Different methods of the cotton modification were investigated (Vasiljevic et al. 2013; Xu et al. 2012; Xue et al. 2009; Yang et al. 2018). Superhydrophobicity of soft woven fabrics can be achieved by coating; the most desirable from the practical point of view are coatings that are thin, transparent and durable (Brzezinski et al. 2012; Ma et al. 2018). To impart superhydrophobicity, modification of surfaces can be carried out, which changes surface energy or increases surface roughness by deposition of particles (Darmanin and Guittard 2015). The latter method was applied recently by (Makowski et al. 2014, 2019) to achieve superhydrophobicity of surfaces of fibrous materials coated with carbon nanoparticles. Trichloromethylosilane (TCMS) in an anhydrous environment was used to form polymethylsilsesquioxane globular particles on the modified surfaces, which resulted in the lotus effect. It was demonstrated that the shape and size of the particles formed on fiber surfaces depended on relative humidity during pre-treatment conditioning of cotton fibers (Artus and Seeger 2014; Makowski et al. 2014). It is worth noting that TCMS hydrophobization of cotton fabric coated with reduced graphene oxide resulted in filament structures on the fiber surfaces (Shateri-Khalilabad and Yazdanshenas 2013). Similar structures were also found on TCMS hydrophobized neat cotton fabric (Shirgholami et al. 2011). Other authors superhydrophobized cotton fabric through treatment with silica nanoparticles and water-repellent agent (Bae et al. 2009), polyphenol (Gu et al. 2017) or industrial waterproof reagent-potassium methyl siliconate ( $\mathrm{Li}$ et al. 2008). The possibility to hydrophobize cotton fabric in the gas phase using fluoromonomers was also explored (Maity et al. 2010).

It is worth noting that silanes other than TCMS, for instance dichloromethylsilane (DCMS), were used to hydrophobize silicon wafers, glass and paper by chemical vapor deposition (Cech et al. 2001) although it is a high-energy method and not always economically viable.

Preparation of hydrophobic or hydrophilic microspheres by a sol-gel method from the functional alkoxysilanes and by cross-linking of polyhydroxysilanes with low molar mass or oligomeric divinyl compounds was recently reviewed (Slomkowski et al. 2017). Based on the described mechanisms it can be envisaged that not only TCMS, but also other silanes can be applied to hydrophobization of a cotton fabric.

It should be noted that the presence of hydroxyl groups on the cellulose surface makes a condensation reaction with silanes possible (Cunha and Gandini 2010; Fadeev and McCarthy 2000). However only one bond in monofunctional organosilane $\left(\mathrm{R}_{3} \mathrm{SiX}\right)$ is hydrolysable; usually $\mathrm{X}=\mathrm{Cl}$ or $\mathrm{N}\left(\mathrm{CH}_{3}\right)_{2}$. Combinations of silica nanoparticles and multifunctional silanes allowed to obtained hydrophobic cotton surfaces (Roe et al. 2012). Recently, bacterial cellulose was hydrophobized with vinyl triethoxysilane or 3-aminopropyl triethoxysilane, and also by acylation and acrylation (Frone et al. 2018).

In this work hydrophobization of cotton fabric using a range of silanes differing in number of chlorine atoms and in other substituents was explored. These compounds were not used previously for such purpose. Water contact angles were measured to characterize hydrophili/phobicity of the modified fabrics and surfaces of the fibers were analyzed using scanning electron microscopy (SEM), SEM with energy dispersive spectroscopy (EDS), attenuated total reflection-Fourier transform infrared spectroscopy (ATRFTIR) and dielectric spectroscopy.

\section{Experimental}

\section{Materials}

Commercial plain weave cotton fabric $\left(145 \mathrm{~g} / \mathrm{m}^{2}\right)$ $0.36 \mathrm{~mm}$ thick, with 205 threads $/ 10 \mathrm{~cm}$ and 295 threads $/ 10 \mathrm{~cm}$ in the warp and weft directions, respectively, was used in this study. Before the modification the cotton fabric was cleaned, as previously described (Makowski et al. 2014). The fabric samples were purified by extraction for $2 \mathrm{~h}$ with diethyl ether ( $98 \%$ p.a. purity) and for next $2 \mathrm{~h}$ in anhydrous ethanol (p.a. purity), both from Chempur, Poland. The samples were then additionally purified 
for $2 \mathrm{~h}$ in boiling ethanol under a reflux condenser, rinsed with doubly distilled water and dried at $120{ }^{\circ} \mathrm{C}$ for $30 \mathrm{~min}$.

The following silanes were used for hydrophobization: trimethylchlorosilane $\mathrm{C}_{3} \mathrm{H}_{9} \mathrm{SiCl}$ (TMCS), dichlorodimethylsilane $\mathrm{C}_{2} \mathrm{H}_{6} \mathrm{Cl}_{2} \mathrm{Si}$ (DMDCS), dichloro(methyl) phenylsilane $\mathrm{C}_{7} \mathrm{H}_{8} \mathrm{Cl}_{2} \mathrm{Si}$ (DCMPhS), 3-chloropropylmethyldichlorosilane $\mathrm{C}_{4} \mathrm{H}_{9} \mathrm{Cl}_{3} \mathrm{Si}$ (CPTCS), (3,3,3-trifluoropropyl)dichloromethylsilane $\mathrm{C}_{4} \mathrm{H}_{7} \mathrm{Cl}_{2} \mathrm{~F}_{3} \mathrm{Si}$ (TFDC MS) and 3-aminopropyl(diethoxy)methylsilane $\mathrm{C}_{8} \mathrm{H}_{21}$ $\mathrm{NO}_{2} \mathrm{Si}$ (AMDES).

TMCS with 98\% purity, was purchased from Fluka Sigma-Aldrich (Germany) whereas DMDCS with 99\% purity, DCMPhS, CPTCS, TFDCMS and AMDES, all four with $97 \%$ purity, were delivered by ABCR (Germany). The structures of the silanes used are shown in Fig. 1.

In addition, hydrochloric acid, 35\%, from Chempur (Poland), toluene p.a. purity from StanLab (Poland), n-hexane, 95\%, from HiPerSolv Chromanorm (Poland), 1,4-dioxane, 99.8\%, from Chem-Lab NV (Belgium) and ethanol, 96\%, from Avantor (Poland) were used.

\section{Hydrophobization of cotton fabric}

Before hydrophobization all fabric samples were conditioned at room temperature (RT) in dessicators under vapors of saturated salt aqueous solutions at relative humidity (RH) of $30 \%$ and $70 \%$ (Makowski et al. 2014).

To impart hydrophobicity, each sample was placed in a polypropylene vessel containing $0.5 \mathrm{M}$ solution of the silane in anhydrous toluene or n-hexane, with exception of 3-aminopropyl(diethoxy)methylsilane, which was dissolved in 1,4-dioxane. $100 \mathrm{ml}$ of solution per $1 \mathrm{~g}$ of fabric was used. The process was carried out at RT for $1 \mathrm{~h}$. The samples were then rinsed sequentially in: toluene, ethanol, ethanol-distilled water mixture (1:1) and distilled water, and then dried in air at RT.

\section{Characterization}

All cotton fabric samples were coated with $10 \mathrm{~nm}$ thick gold layer by ion sputtering using a coater Quorum EMS150R ES (UK) and then analyzed with SEM JSM-6010LA JEOL (Japan) with EDS.

ATR-FTIR spectra of the neat and modified fabric were recorded on a FT/IR-6200 Jasco (Germany) spectrometer equipped with ATR PRO610P-S device.

To determine water contact angles (WCA), $5 \mu \mathrm{l}$ distilled water droplets were placed on surfaces of the materials at $25^{\circ} \mathrm{C}$. WCA values were measured using a RameHart NRL Goniometer, 100-00-230 (RameHart, NJ) coupled with a camera and optical system. Determination of WCA values was carried out using Drop Analysis program. To obtain average values, the measurements were repeated five times for three samples of each material and the results were averaged.

The impedance spectra in the frequency range of $20 \mathrm{~Hz}-1 \mathrm{MHz}$ were determined using a HP4284A precision RLC meter, with sinusoidal signal with $20 \mathrm{~V}$ amplitude. The samples were sandwiched between<smiles>C[Si](C)(C)Cl</smiles>

(1)<smiles>C[Si](Cl)(Cl)CCCCl</smiles>

(4)<smiles>C[Si](C)(Cl)Cl</smiles>

(2)<smiles>C[Si](Cl)(Cl)CCC(F)(F)F</smiles>

(5)<smiles>C[Si](Cl)(Cl)c1ccccc1</smiles>

(3)

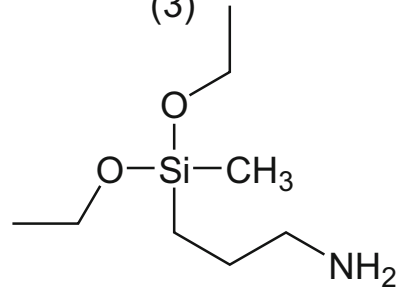

(6)

Fig. 1 Structures of siloxanes: (1) trimethylchlorosilane; (2) dichlorodimethylsilane; (3) dichloro(methyl)phenylsilane; (4) 3-chloropropylmethyldichlorosilane; (5) (3,3,3-trifluoropropyl)dichloromethylsilane; (6) 3-aminopropyl(diethoxy)methylsilane 
two copper electrodes in the form of disks with $10 \mathrm{~mm}$ in diameter, and connected to the measurement unit with $1 \mathrm{~m}$ cable. The distance between the two electrodes was constant and equal to $301 \mu \mathrm{m}$.

\section{Results and discussion}

Photographs of water droplets on surfaces of the modified fabric samples are shown in Table 1 together with corresponding WCA values. The untreated cotton samples as well as those treated with AMDES and TMCS were hydrophilic and water droplets soaked in. In the case of DMDCS, DCMPhS, CPTCS and TFDCMS, superhydrophobicity was achieved, reflected in WCA angles $157-165^{\circ}$ and $163-174^{\circ}$, after conditioning at $\mathrm{RH}$ of $30 \%$ and $70 \%$, respectively. The higher $\mathrm{RH}$ during the conditioning increased the WCA values, similarly as reported previously (Makowski et al. 2014). In turn, the type of solvent used had no significant effect on the WCA values, except for CPTCS and TFDCMS treatment of fabric conditioned at $\mathrm{RH}$ of $30 \%$, for which the use of n-hexane as a solvent increased somewhat these values. Most possibly, due to a smaller content of residual water in $n$-hexane, the reactions leading the hydrophobization (described below) were more localized on fiber surfaces. It is worth noting that the effect vanished for the fabric samples conditioned at $\mathrm{RH}$ of $70 \%$ due to higher water content in the fabric.

Surfaces of neat cotton fibers are presented in Fig. 2 showing surface roughness on a microscale, resulting from the presence of microfibrils (Brzezinski et al. 2012). The silane treated surfaces are shown in Fig. 3.

Except for Fig. 3a, which shows fiber surface very similar to that of neat cotton fiber, thin layers and particles resulting from silane treatment are visible. Small cracks in the layers, occasionally seen, resulted most probably from damage caused by the electron beam. However, the surface topography is different than that described previously (Makowski et al. 2014). No evenly distributed spherical objects or filament

Table 1 Water contact angles (WCA) for untreated cotton fabric and cotton fabric samples conditioned at RH of 30 and $70 \%$, and then treated with silanes in toluene $\left(\mathrm{WCA}_{t}\right)$ and in n-hexane $\left(\mathrm{WCA}_{\mathrm{h}}\right)$. The asterisk denotes that 1,4-dioxane was used as a solvent

\begin{tabular}{|c|c|c|c|c|}
\hline \multirow{2}{*}{ Reagents } & \multicolumn{2}{|c|}{ RH $30 \%$} & \multicolumn{2}{|c|}{ RH $70 \%$} \\
\hline & $\mathrm{WCA}_{t}\left({ }^{\circ}\right)$ & $\mathrm{WCA}_{\mathrm{h}}\left({ }^{\circ}\right)$ & $\mathrm{WCA}_{\mathrm{t}}\left({ }^{\circ}\right)$ & $\mathrm{WCA}_{\mathrm{h}}\left({ }^{\circ}\right)$ \\
\hline $\begin{array}{l}\text { Untreated } \\
\text { cotton }\end{array}$ & \multicolumn{2}{|c|}{ Soak } & \multicolumn{2}{|c|}{ Soak } \\
\hline AMDES* & \multicolumn{2}{|c|}{ Soak } & \multicolumn{2}{|c|}{ Soak } \\
\hline TMCS & \multicolumn{2}{|c|}{ Soak } & \multicolumn{2}{|c|}{ Soak } \\
\hline DMDCS & 163 & 164 & 168 & 169 \\
\hline DCMPhS & 164 & 165 & 167 & 169 \\
\hline CPTCS & 154 & 158 & 174 & 174 \\
\hline TFDCMS & 157 & 163 & 172 & 172 \\
\hline
\end{tabular}

*1,4-Dioxane 

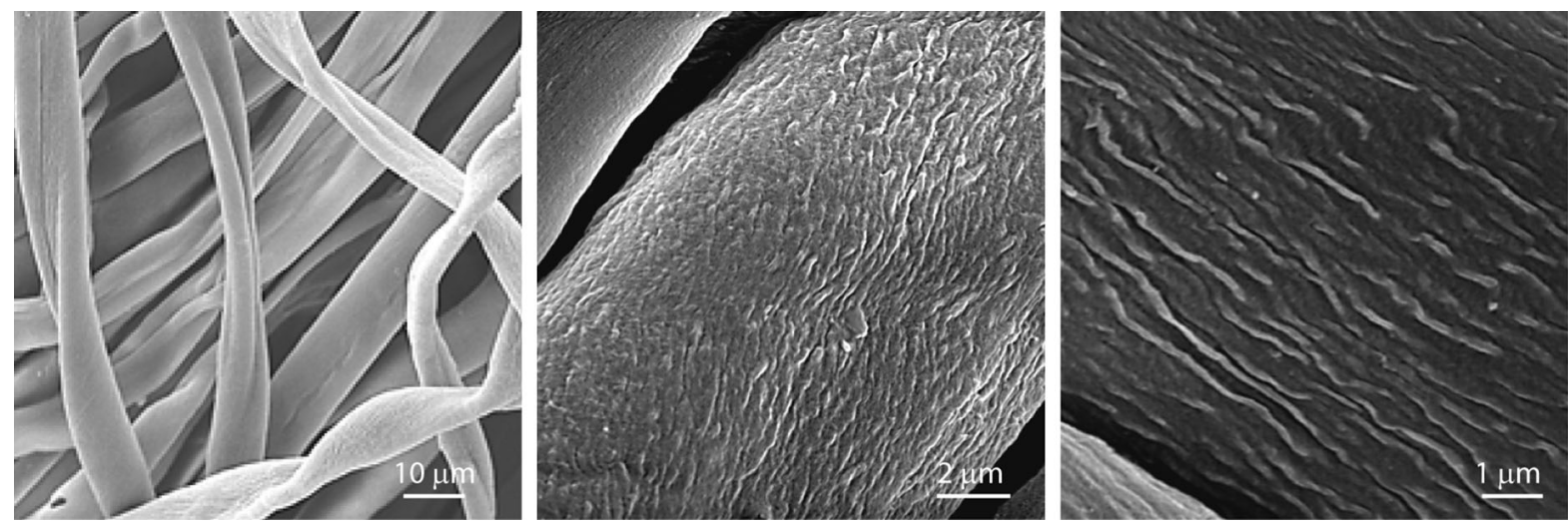

Fig. 2 SEM micrographs of neat cotton fibers

$\mathrm{RH} 30 \%$
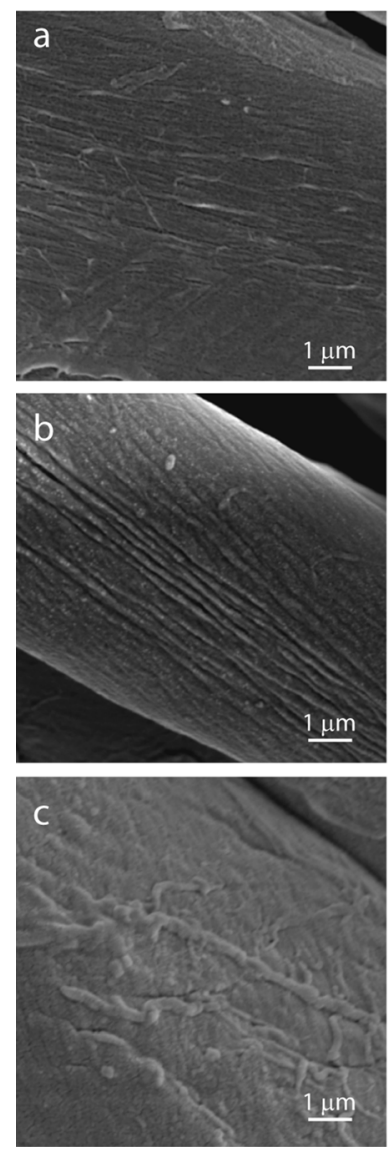
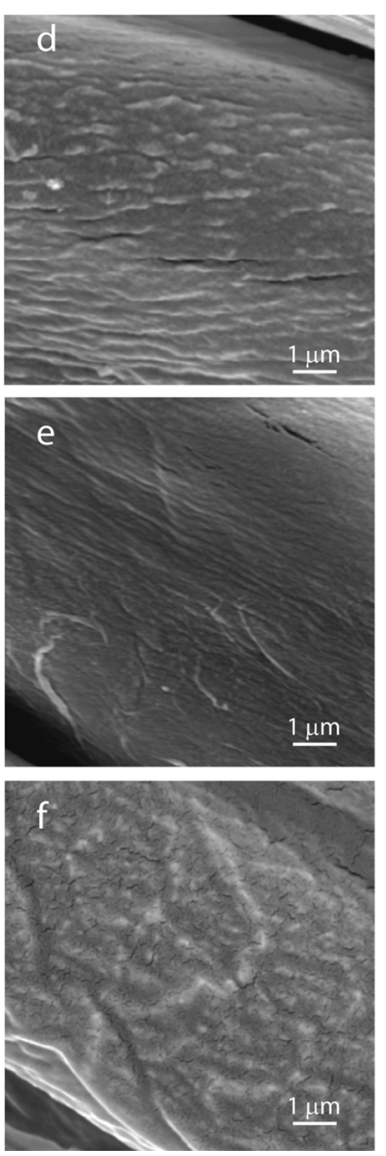
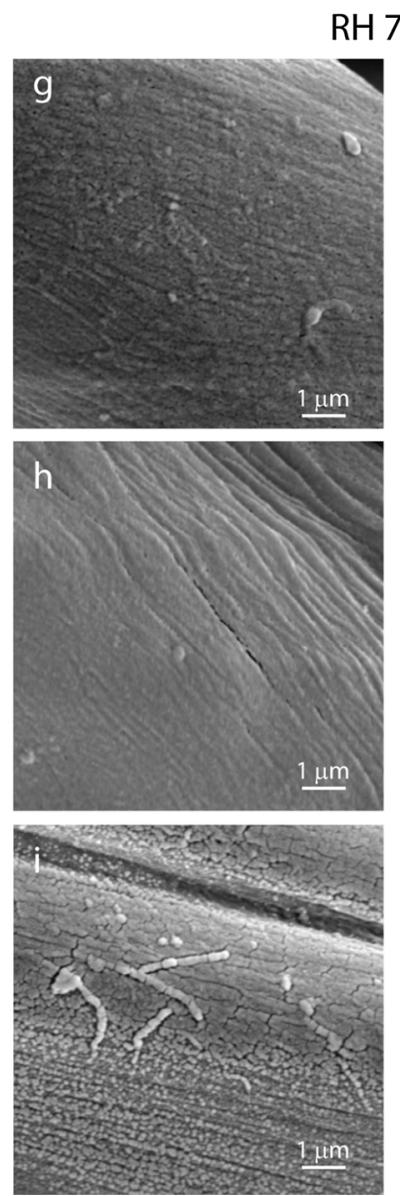

$\mathrm{RH} 70 \%$
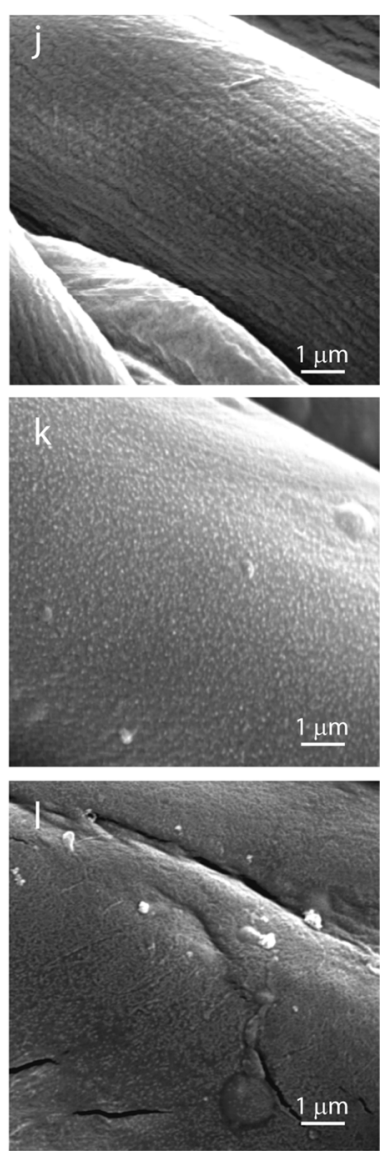

Fig. 3 SEM images of cotton fiber surfaces after treatment with silanes dissolved in toluene: a, $\mathbf{g}$ TMCS, b, h DMDCS, c, i DCMPhS, $\mathbf{d}, \mathbf{j}$ CPTCS, e, $\mathbf{k}$ TFDCMS, f, l AMDES after conditioning at RH of $30 \%$ (a-f) or $70 \%(\mathbf{g}-\mathbf{l})$

structures were clearly discernible on the surfaces studied unlike in (Makowski et al. 2014; Shirgholami et al. 2011). Exemplary EDS spectra for silane treated fabric samples, conditioned previously at RH of $70 \%$, are shown in Fig. 4. Very similar results were obtained for samples conditioned at RH of $30 \%$ (not shown). 
(a)

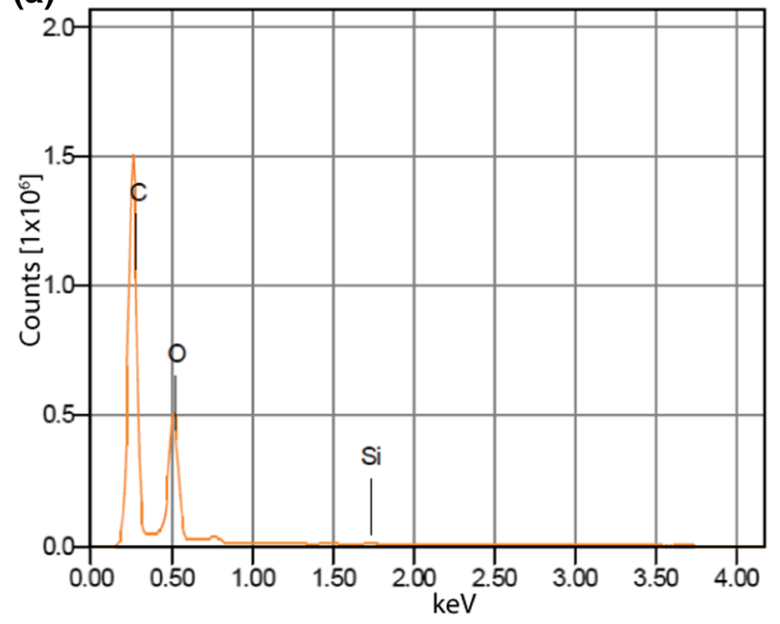

(b)

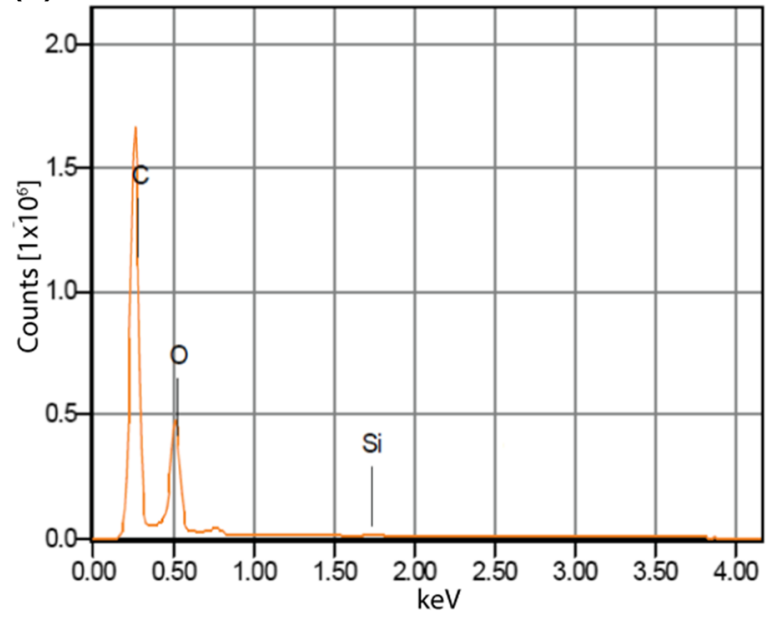

(c)

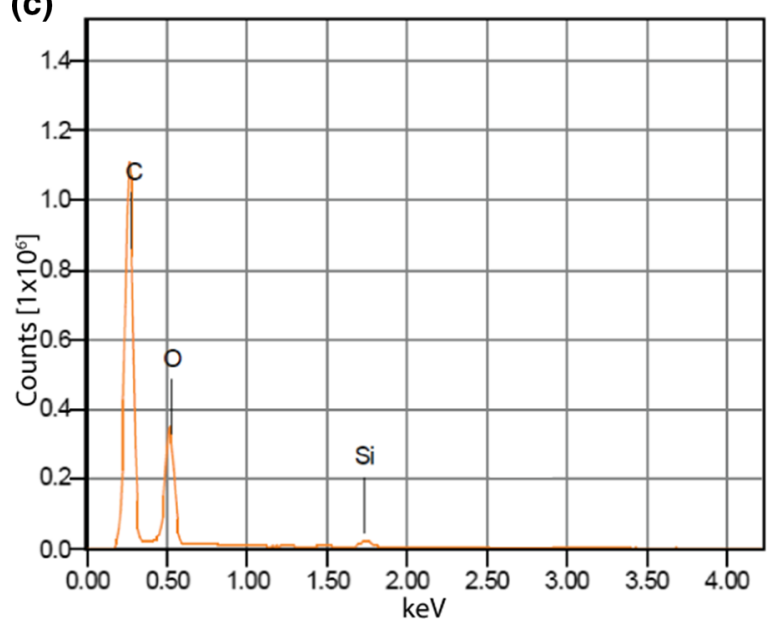

(d)

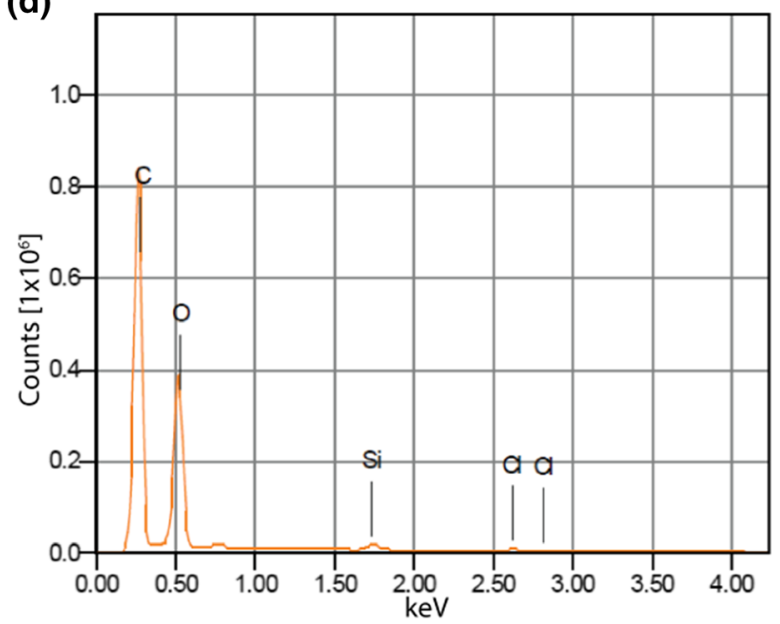

(e)

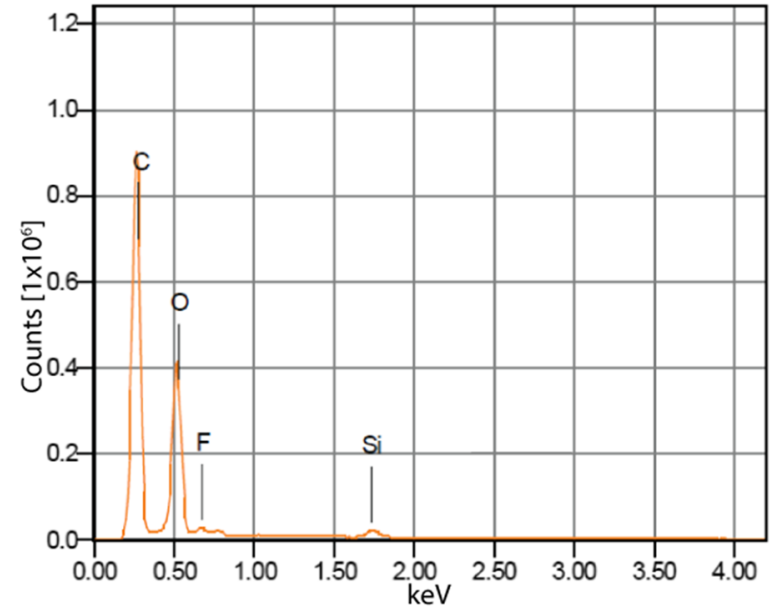

(f)

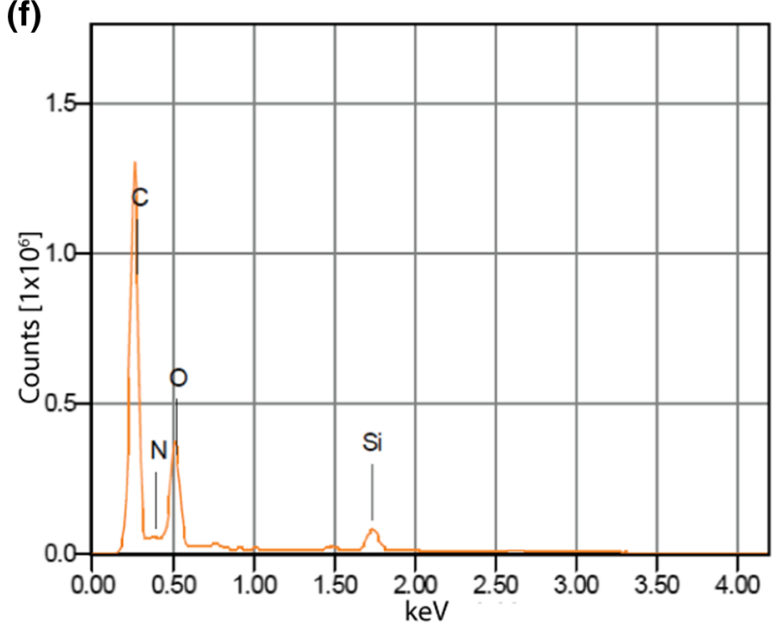

Fig. 4 EDS spectra of cotton fabric samples conditioned at RH of 70\%, and treated with silanes dissolved in toluene: a TMCS, b DMDCS, c DCMPhS, d CPTCS, e TFDCMS, f AMDES 
All spectra demonstrated the presence of $\mathrm{Si}$, which evidences the deposition of reaction products on the fiber surfaces.

The probable mechanisms of hydrolysis and condensation reactions are shown Fig. 5. The first step was reaction with water molecules loosely associated with cotton or residual water molecules in solvents, which resulted in formation of silanol groups, capable of condensation reaction. In all cases linking of reaction products to cotton was possible through condensation involving cotton hydroxyl groups. Hydrolysis and condensation reactions of silanes with two $\mathrm{Cl}$ atoms bound to $\mathrm{Si}$ atom can result in the formation of linear oligomers/polymers, that form a hydrophobic coating on the surface of the fiber. This explains superhydrophobicity of the fiber surfaces treated with DMDCS, DCMPhS, CPTCS and TFDCMS. It is worth noting that only on the surface of CPTCS treated fibers the presence of $\mathrm{Cl}$ was shown by EDS, most probably because $\mathrm{Cl}$ in the chloropropyl group remained unreacted, being less reactive than $\mathrm{Cl}$ atoms bonded directly to Si (Rozga-Wijas et al. 2010). In the case of AMDES the condensation reactions are also possible but the presence of $-\mathrm{NH}_{2}$ end groups makes the resulting coating hydrophilic.

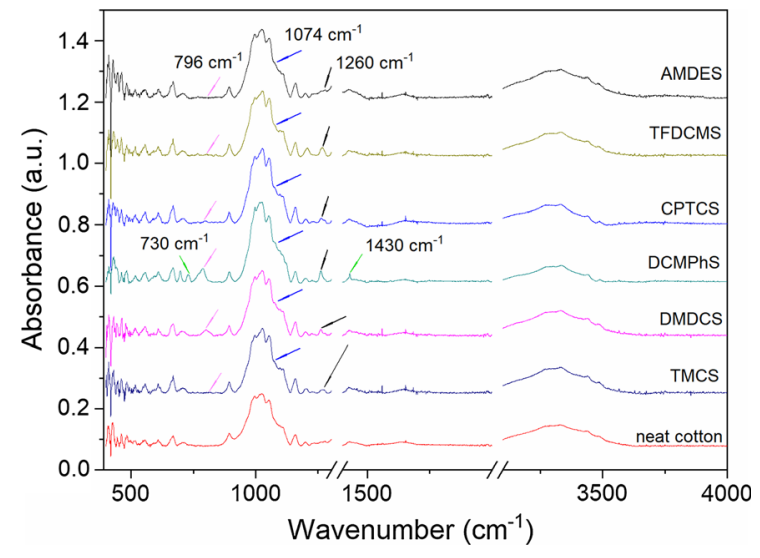

Fig. 6 ATR-FTIR spectra of neat and modified cotton fabric

ATR-FTIR spectra of the neat and modified cotton fabric are shown in Fig. 6. Bands characteristic of polysiloxanes are indicated with arrows: at $789-796 \mathrm{~cm}^{-1}\left(-\mathrm{CH}_{3}\right.$ rocking and $\mathrm{Si}-\mathrm{C}$ stretching in $\left.\mathrm{Si}-\mathrm{CH}_{3}\right)$, at $1074 \mathrm{~cm}^{-1}$ ( $\mathrm{Si}-\mathrm{O}-\mathrm{Si}$ stretching), at $1260-1259 \mathrm{~cm}^{-1} \quad\left(\mathrm{CH}_{3}\right.$ deformation in $\left.\mathrm{Si}-\mathrm{CH}_{3}\right)$ (Johnson et al. 2013). Bands at $730 \mathrm{~cm}^{-1}$ and $1430 \mathrm{~cm}^{-1}$ are characteristic of $\mathrm{Si}-\mathrm{Ph}$, the latter very narrow (Launer and Arkles 2013). It must be added that those bands are weak, because the coatings are (a)

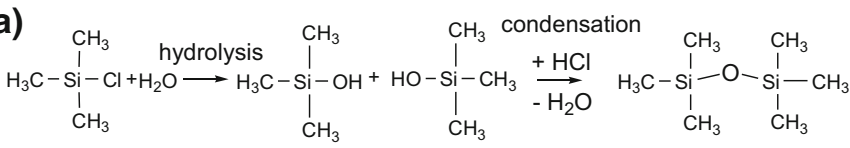

(b)

$$
\text { (b) }
$$

(c)

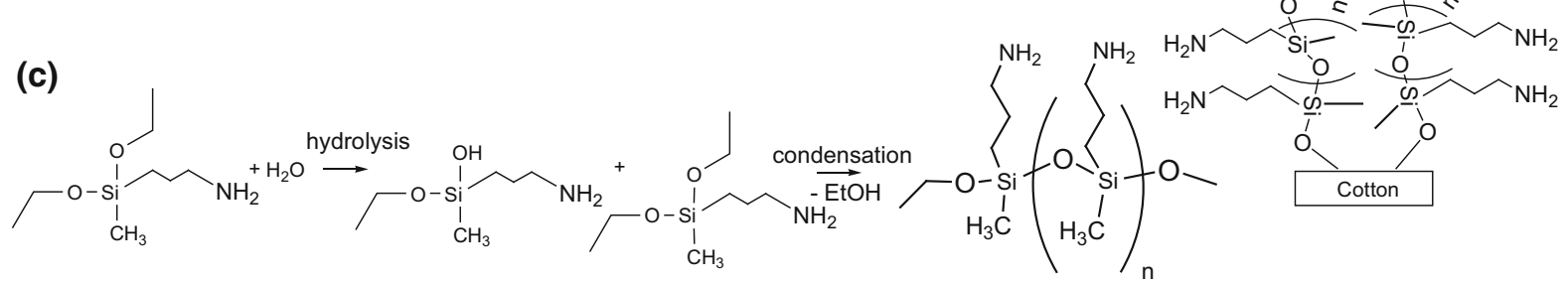

Fig. 5 Schemes of reactions during treatment of cotton fibers with: a TMCS, b DMDCS, DCMPhS, CPTCS, TFDCMS, c AMDES 


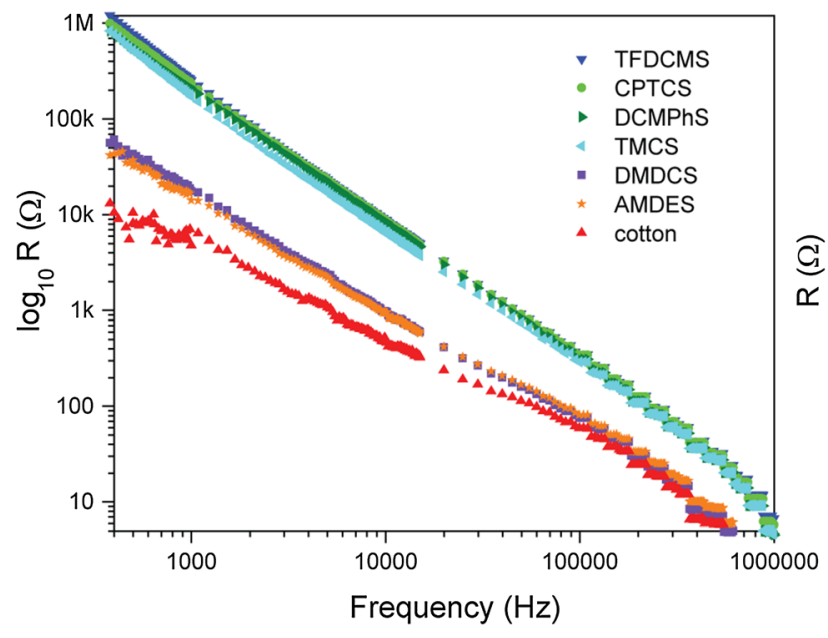

Fig. 7 Impedance spectroscopy of neat and modified cotton fabric

very thin and the spectra are dominated by signals of cotton.

Figure 7 shows frequency dependence of resistance (real part of impedance), R, of the modified and neat cotton and the value of $\mathrm{R}$ at $500 \mathrm{~Hz}$.

It can be seen that after the modification with TCMS, DCMPhS, CPTCS and TFDCMS R increased, especially at low frequency. $\mathrm{R}$ is most possible related to the presence of water associated with cotton and its increase reflects efficiency of reactions leading to removal of water from the fibers.

\section{Conclusions}

Treatment of cotton fabric with a range of commercially available silanes, with different numbers of chlorine atoms and different substituents, was explored. Superhydrophobicity of the fabric was achieved after $1 \mathrm{~h}$ treatment with DMDCS, DCMPhS, CPTCS and TFDCMS dissolved in anhydrous solvents. As a result of the treatment, the surfaces were coated although globular or filament structures, like those oberved previoulsly in the case of TCMS treatment (Makowski et al. 2014; Shirgholami et al. 2011), were absent. AMDES and TMCS treatment was inefficient, and did not impart hydrophobicity to the cotton fabric. Hydrolysis and condensation reactions of silanes with two $\mathrm{Cl}$ atoms bound to $\mathrm{Si}$ atom can result in the formation of linear oligomeric structures that form a hydrophobic coating on the

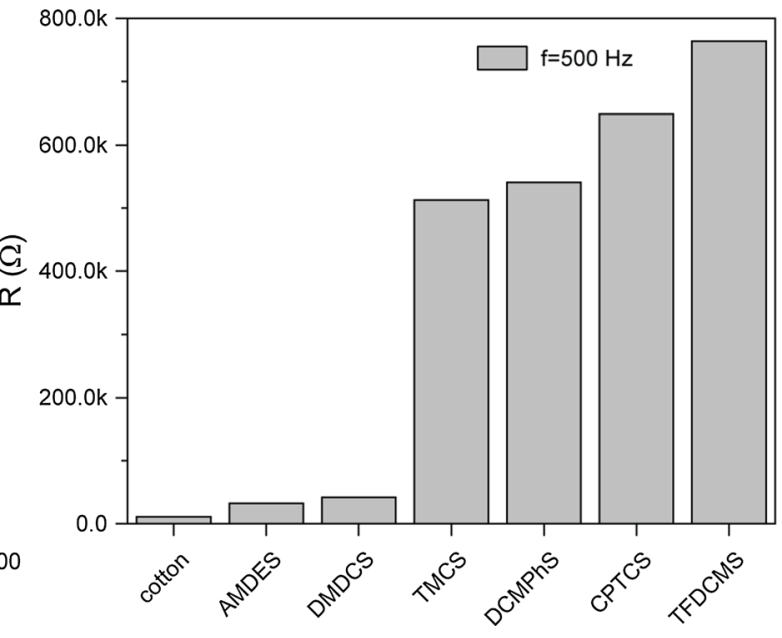

surface of the fibers. The ATR-FTIR spectra confirmed the modification of the cotton fabric with the siloxane compounds. The results obtained can contribute to optimization of technological processes of hydrophobization of cotton textiles.

Acknowledgments The financial support of this work from the National Science Centre, Poland (UMO-2014/15/B/ST8/ 04286) is acknowledged.

Open Access This article is distributed under the terms of the Creative Commons Attribution 4.0 International License (http:// creativecommons.org/licenses/by/4.0/), which permits unrestricted use, distribution, and reproduction in any medium, provided you give appropriate credit to the original author(s) and the source, provide a link to the Creative Commons license, and indicate if changes were made.

\section{References}

Artus GRJ, Seeger S (2014) One-dimensional silicone nanofilaments. Adv Colloid Interface 209:144-162. https://doi. org/10.1016/j.cis.2014.03.007

Bae GY, Min BG, Jeong YG, Lee SC, Jang JH, Koo GH (2009) Superhydrophobicity of cotton fabrics treated with silica nanoparticles and water-repellent agent. J Colloid Interface Sci 337:170-175. https://doi.org/10.1016/j.jcis.2009.04. 066

Brzezinski S, Kowalczyk D, Borak B, Jasiorski M, Tracz A (2012) Applying the sol-gel method to the deposition of nanocoats on textiles to improve their abrasion resistance. J Appl Polym Sci 125:3058-3067. https://doi.org/10.1002/ app.36353

Cech V, Horvath P, Trchova M, Zemek J, Matejkova J (2001) Analysis of annealed thin polymer films prepared from 
dichloro(methyl)phenylsilane by plasma polymerization. J Appl Polym Sci 82:2106-2112. https://doi.org/10.1002/ app. 2056

Cunha AG, Gandini A (2010) Turning polysaccharides into hydrophobic materials: a critical review. Part 1. Cellulose. Cellulose 17:875-889. https://doi.org/10.1007/s10570010-9434-6

Darmanin T, Guittard F (2015) Superhydrophobic and superoleophobic properties in nature. MaterToday 18:273-285. https://doi.org/10.1016/j.mattod.2015.01.001

Fadeev AY, McCarthy TJ (2000) Self-assembly is not the only reaction possible between alkyltrichlorosilanes and surfaces: monomolecular and oligomeric covalently attached layers of dichloro- and trichloroalkylsilanes on silicon. Langmuir 16:7268-7274. https://doi.org/10.1021/la0004 $71 \mathrm{z}$

Frone AN, Panaitescu DM, Chiulan I, Nicolae CA, Casarica A, Gabor AR, Trusca R, Damian CM, Purca V, Alexandrescu E, Stanescu PO (2018) Surface treatment of bacterial cellulose in mild, eco-friendly conditions. Coatings 8:17. https://doi.org/10.3390/coatings8060221

Gu SJ, Yang L, Huang W, Bu YM, Chen DZ, Huang JJ, Zhou YS, Xu WL (2017) Fabrication of hydrophobic cotton fabrics inspired by polyphenol chemistry. Cellulose 24 : 2635-2646. https://doi.org/10.1007/s10570-017-1274-1

Johnson LM, Gao L, Shields CW, Smith M, Efimenko K, Cushing K, Genzer J, López GP (2013) Elastomeric microparticles for acoustic mediated bioseparations. J Nanobiotechnol 11:22. https://doi.org/10.1186/14773155-11-22

Launer PJ, Arkles B (2013) Infrared analysis of organosilicon compounds: spectra-structure correlations. In: Arkles B, Larson GL (eds) Silicon compounds: silanes and silicones, pp 177-180

Li SH, Zhang SB, Wang XH (2008) Fabrication of superhydrophobic cellulose-based materials through a solutionimmersion process. Langmuir 24:5585-5590. https://doi. org/10.1021/la800157t

Ma YL, Cao CJ, Hou CM (2018) Preparation of super-hydrophobic cotton fabric with crosslinkable fluoropolymer. Lect Notes Electr Eng 477:955-962. https://doi.org/10. 1007/978-981-10-7629-9_119

Maity J, Kothary P, O'Rear EA, Jacobi C (2010) Preparation and comparison of hydrophobic cotton fabric obtained by direct fluorination and admicellar polymerization of fluoromonomers. Ind Eng Chem Res 49:6075-6079. https:// doi.org/10.1021/ie100564y

Makowski T, Kowalczyk D, Fortuniak W, Jeziorska D, Brzezinski S, Tracz A (2014) Superhydrophobic properties of cotton woven fabrics with conducting $3 \mathrm{D}$ networks of multiwall carbon nanotubes, MWCNTs. Cellulose 21:4659-4670. https://doi.org/10.1007/s10570-014-0422-0

Makowski T, Zhang C, Olah A, Piorkowska E, Baer E, Kregiel D (2019) Modification of dual-component fibrous materials with carbon nanotubes and methyltrichlorosilane. Mater Design 162:219-228. https://doi.org/10.1016/j.matdes.2018. 11.026

Roe B, Kotek R, Zhang X (2012) Durable hydrophobic cotton surfaces prepared using silica nanoparticles and multifunctional silanes. J Text I 103:385-393. https://doi.org/10. 1080/00405000.2011.580540

Rozga-Wijas K, Fortuniak W, Kowalewska A, Chojnowski J (2010) Generation of 3-chloropropylsilanetriol: monomer for the synthesis of 3-chloropropyl substituted oligosilsesquioxanes. J Inorg Organomet Polym 20:387-394. https://doi.org/ 10.1007/s10904-010-9351-z

Shateri-Khalilabad M, Yazdanshenas ME (2013) Preparation of superhydrophobic electroconductive graphene-coated cotton cellulose. Cellulose 20:963-972. https://doi.org/10. 1007/s10570-013-9873-y

Shirgholami MA, Khalil-Abad MS, Khajavi R, Yazdanshenas ME (2011) Fabrication of superhydrophobic polymethylsilsesquioxane nanostructures on cotton textiles by a solution-immersion process. J Colloid Interface Sci 359:530-535. https://doi.org/10.1016/j.jcis.2011.04.031

Slomkowski S, Fortuniak W, Chojnowski J, Pospiech P, Mizerska U (2017) Polysiloxane microcapsules, microspheres and their derivatives. Polimery 62:499-508. https://doi. org/10.14314/polimery.2017.499

Vasiljevic J, Gorjanc M, Tomsic B, Orel B, Jerman I, Mozetic M, Vesel A, Simoncic B (2013) The surface modification of cellulose fibres to create super-hydrophobic, oleophobic and self-cleaning properties. Cellulose 20:277-289. https:// doi.org/10.1007/s10570-012-9812-3

Xu LH, Zhuang W, Xu B, Cai ZS (2012) Superhydrophobic cotton fabrics prepared by one-step water-based sol-gel coating. J Text Inst 103:311-319. https://doi.org/10.1080/ 00405000.2011.569238

Xue CH, Jia ST, Zhang J, Tian LQ (2009) Superhydrophobic surfaces on cotton textiles by complex coating of silica nanoparticles and hydrophobization. Thin Solid Films 517:4593-4598. https://doi.org/10.1016/j.tsf.2009.03.185

Yang J, Pu Y, Miao DG, Ning X (2018) Fabrication of durably superhydrophobic cotton fabrics by atmospheric pressure plasma treatment with a siloxane precursor. Polymers 10:460. https://doi.org/10.3390/polym 10040460

Publisher's Note Springer Nature remains neutral with regard to jurisdictional claims in published maps and institutional affiliations. 